\title{
Indigenous identification: Past, present and a possible future
}

\author{
Richard Madden ${ }^{\mathrm{a}}$, Clare Coleman ${ }^{\mathrm{a}, *}$, Angela Mashford-Pringle ${ }^{\mathrm{b}}$ and Michele Connolly ${ }^{\mathrm{c}}$ \\ ${ }^{a}$ Faculty of Health Sciences, University of Sydney, Sydney, Australia \\ ${ }^{\mathrm{b}}$ Dalla Lana School of Public Health, University of Toronto, Toronto, ON, Canada \\ ${ }^{\mathrm{c}}$ International Group for Indigenous Health Measurement, Statistical Journal of the IAOS
}

\begin{abstract}
This overview paper for the special issue of the journal on Indigenous identification is designed to provide the reader with some background information on the methodologies of Indigenous identification. The United Nations Permanent Forum on Indigenous Issues' definition is provided and the brief review of the methodologies of Australia, Brazil, Canada, New Zealand and United States of America are examined in the light of this definition. Some other common methodologies are also presented. The consequences of these methodologies are considered and the need for Indigenous engagement with Statistical Agencies is explored.
\end{abstract}

Keywords: Indigenous identification, official statistics

\section{Introduction}

Many Indigenous societies are characterised and labelled by settler or colonising group(s). The settlers or colonisers decided on their own identification principles for the Indigenous people with whom they were in contact. Not surprisingly, these principles served the purpose of the settler or coloniser.

Moreover, in the early stages of settlement or colonisation, it was not difficult to determine who was Indigenous: they were not 'us', the settlers or colonisers.

The Indigenous people's views on identification methods were typically not sought, and there continues to be a lack of consultation on identification. In the United States of America (US), Canada and Australia, identification of Indigenous people was designed to exclude [1]. In the US Constitution, a census was mandated to count citizens “.... excluding Indians not taxed" [2]. In Australia, mirroring this earlier provision in the United States Constitution, Section 127 of the

\footnotetext{
${ }^{*}$ Corresponding author: Clare Coleman, Faculty of Health Sciences, University of Sydney, Sydney, Australia. E-mail: Clare. Coleman@sydney.edu.au.
}

1901 Constitution specified that in reckoning the population, Aboriginal natives should not be counted. So identification was to exclude, not include.

Other colonisers entered into treaties with Indigenous peoples, and it became important to identify those covered by these treaties. This led in another direction in Canada: descent from a parent covered by the treaty.

A further variant, notably in Scandinavia, arises from a more modern desire not to discriminate among citizens: so do not identify at all.

The result is a wide range of methods for identifying Indigenous peoples. These methods did not reflect the views of Indigenous peoples as to who they were, nor any desire to enumerate Indigenous people consistently in different data collections.

\section{Definition of Indigenous peoples}

The United Nations Permanent Forum on Indigenous Issues (UNPFII) has now set out seven criteria for the identification of Indigenous peoples [3]:

- self-identification as Indigenous peoples at the individual level and accepted by the community as a member 
- historical continuity with pre-colonial or presettler societies

- strong link to territories and surrounding natural resources

- distinct social, economic, or political systems

- distinct language, culture, and beliefs

- people from non-dominant groups of society

- resolve to maintain and reproduce their ancestral environments and systems as distinctive peoples and communities.

However, far narrower approaches have been used in the past by governments and statistical agencies. Indigenous people have not been involved in setting these approaches to identification until recent years. Even with Indigenous input, the identification is fraught with issues including where identity is acquired (census, community, government documents, etc.), or who can claim their Indigenous ancestry and what community has accepted the individual.

\section{Indigenous identification approaches}

\subsection{Race}

This tended to be the starting method. An Indigenous person would be determined by the percentage of Indigenous blood in their veins. In Australia, more than 50 percent made a person an Aboriginal native, and resulted in the person's exclusion from population estimates.

The term 'race' has been used to the current day, for example in the US census. It is important to note that the same self reported racial questions are included on all federal surveys and vital statistics. American Indian and/or Alaska Native is defined as “... a person having origins in any of the original people of North and South America (including Central America) and who maintains tribal affiliation or community attachment". For those who report themselves as American Indian or Alaska Native, space is provided to record their tribal affiliation. The Indigenous people of Hawaii and other Pacific Islands are defined as “... a person having origins in any of the original peoples of Hawaii, Guam, Samoa, or other Pacific Islands." On the census, separate boxes for Native Hawaiian, Guamanian or Chamorro, Samoan and Other Pacific Islander can be marked. In the latter instance, space is provided to record race, such as Fijian or Tongan [4].

\subsection{Genealogy}

Rather than asking a person's race, their descent could be sought. This was particularly appropriate where descent made a person eligible for treaty rights. Such an approach applies to First Nations peoples in Canada, where descent from a particular tribe gives rights under specific treaties. However, there can be arbitrary bars on identification where apparent assimilation is used as a bar to identification. Variants apply: descent from father may give a different answer to descent from mother.

\subsection{Legal}

In the US, the identification of American Indians and Alaska Natives who are members of federallyrecognized Tribes are based on legal, as well as genealogical factors. There are currently 573 federallyrecognized Tribes with a sovereign (nation-to-nation) relationship with the government based on treaties with Congress, executive orders from the President, court decisions and/or administrative procedures. Enrolled members of these tribes must meet legal criteria from their individual tribes. A common criterion is onefourth or more blood quantum. Members of federallyrecognized Tribes are eligible for certain programs, such as the Indian Health Service.

\subsection{Origin, ethnicity}

As more Indigenous people inter-married with nonIndigenous peoples, broader definitions were introduced. In Canada, 'a new Aboriginal people emerged - the Métis people - with their own unique culture, traditions, language (Michif), way of life, collective consciousness and nationhood' [5]. Genealogy is necessary to be Métis, but it includes much more: 'Genealogical ties, a common history, economic networks, language, culture, religion and the Métis way of life all contributed to the construction and maintenance of the boundaries of the Métis Nation' [6].

In Australia, Aboriginal or Torres Strait Islander origin became the identifier from the 1980s, distinct from questions about country of birth and language spoken at home to distinguish other ethnic groups. New Zealand asked an ethnic origin question which included Indigenous (Maori) as an option since the Statistic Act of 1955.

The approaches used in Australia and New Zealand follow the first UNPFII criterion set out above, but do 
not touch on the others. There is a need for Indigenous peoples in each country to develop and promote the criteria they consider essential to identification. The approach has to be amenable to implementation by statisticians and administrators, so a meeting of minds is demanded.

\subsection{Proxy measures}

When there is no specific identification of Indigenous people in a country, resort is sometimes had to alternative proxy measures such as geographical region or language spoken. A 2016 Lancet review of Indigenous Health noted: 'Proxy measures have policy value by guiding service development with potential flowon benefits to Indigenous peoples. However, caution is required in the use of proxy measures to make inferences on Indigenous health status. This approach is especially the case for Sweden where the geographical proxies are Sami Administrative Areas, with a Sami population 18 years and older of 9-13 percent of the total population. At this population density, we have concerns about the accuracy of this picture of Sami health status, in view of reports of increased rates of morbidity and mortality due to suicide, accident, and injury' [7].

\section{Who does the identifying?}

In population censuses, people typically selfidentify. This was not always the case. In Canada, Indian agents or data collectors had the ability to determine a First Nations person's identity as it pertained to the Indian Act (for registration purposes). In Canada, the federal government determined band/tribal locations and members without the communities having any input; this has changed in the past 50 years, but previous enrolments or enfranchisements have continued effects today. In the US, until about 1930 (after the enactment of the Indian Citizenship Act in 1924), Indian agents collected data on American Indians residing on reservations. There were no consistent standards nor were copies made. Census enumerators recorded data until 1960, when self-reports began. In 1960, the racial category of American Indian and Alaska Native was added [8]. The reporting of multiple races was allowed, starting 2000. Tribes and American Indian groups have been and continue to be consulted in participation, design and analysis, but these efforts need to be heightened. Attempts to get American Indi- ans and Alaska Natives to participate in the US census have been largely successful. The design component was set in stone with the Office of Management and Budget Standard in 1997 on Race, However, examples can be added or changed. In 2020, the census will include examples of tribes for the space to write principal tribes [9]. Analysis efforts with the tribes need to be amplified.

In other data collections, the identifier can vary, even where self-identification is the apparent method. In a hospital, an admissions clerk may identify, either by asking the person or a family member, or making their own decision, possibly guided by appearance. In a justice setting, the identification may be by a police or custodial official. For a deceased person, a funeral director may make the identification without consultation with family members.

Identification when a birth is registered is an important issue, both for statistical purposes (e.g., estimation of child mortality) and where legal rights depend on accepted identification. Canada no longer identifies Indigenous children at birth registration.

There has historically been social stigma associated with being Indigenous. This may influence an Indigenous person as to whether to identify or not: service or care may be affected or presumed to be affected by the decision. Where others identify, there may be an assumption that the person is Indigenous based on the circumstances at the time.

Some Indigenous people are only beginning to selfidentify as Indigenous as there has been a shift with societies accepting Indigeneity more, but there are social, economic and political reasons at an individual level that may influence a person's decision to identify as Indigenous. The popularity of ancestry companies advertising genetic ancestry may have an effect and may continue to be more important, especially in the US where the reporting of multiple races is allowed. In the US, ancestry companies are not able to identify lineage for specific tribes, so cannot be used for purposes of tribal enrollment.

\section{Current state of Identification in selected countries}

In this special issue of the journal, practices in Australia, Brazil, Canada, New Zealand and the US are being considered. Identification in these countries varies considerably. Table 1 outlines the methods of identification used in census data collection and in vital 
Table 1

Presence of Indigenous identifier in selected data sets and method of identification

\begin{tabular}{lcccl}
\hline \multicolumn{1}{c}{ Country } & Census & Birth registration & Death registration & \multicolumn{1}{c}{ Method } \\
\hline Australia & Yes & Yes & Yes & Self-identification \\
Brazil & Yes & No & No & Race \\
Canada & Some & No & No & Long form census \\
New Zealand & Yes & Yes & Yes & Self-identification \\
United States & Yes & Yes & Yes & Race \\
\hline
\end{tabular}

Table 2

Identification question used in most recent census

\begin{tabular}{|c|c|}
\hline Country & Identification question \\
\hline Australia & "Are you of Aboriginal or Torres Strait Islander origin?", with the options No., Yes Aboriginal. or Yes Torres Strait Islander. \\
\hline Brazil & $\begin{array}{l}\text { "What is your color or race?", with the options White, Yellow, Brown, Black, and Indigenous (Branca, Amarela, Parda, } \\
\text { Preta, and Indígena). }\end{array}$ \\
\hline Canada & $\begin{array}{l}\text { "Is this person an Aboriginal person, that is, First Nations (North American Indian), Métis or Inuk (Inuit)?", with the } \\
\text { options No, not an Aboriginal person. Yes, First Nations (North American Indian). Yes, Métis Yes, Inuk (Inuit). }\end{array}$ \\
\hline New Zealand & $\begin{array}{l}\text { "Which ethnic group do you belong to?", with the options New Zealand European, Maori, Samoan, Cook Island Maori, } \\
\text { Tongan, Niuean, Chinese, Indian, Other. }\end{array}$ \\
\hline $\begin{array}{l}\text { United States } \\
\text { of America }\end{array}$ & $\begin{array}{l}\text { "What is this person's race", mark one or more boxes. White; Black, African American or Negro; American Indian or } \\
\text { Alaska Native - print name of principal tribe; Asian Indian, Chinese; Filipino; Japanese; Koran; Vietnamese; Other Asian - } \\
\text { write type; Native Hawaiian; Guamanian or Chamorro; Samoan; Other Pacific Islander - write type; and Some other race. } \\
\text { For the next census in 2020, it is planned that examples of tribes will be provided. And that Negro will no longer be stated } \\
\text { under Black. Space will also be provided to record more detailed ancestry for Whites, Blacks and Some Other Race. }\end{array}$ \\
\hline
\end{tabular}

statistics collections. Table 2 displays the identification question used in the most recent census for each country.

\section{What are the consequences of Identification practices?}

If Indigenous people are not identified in statistical collections, then they will be invisible in national reporting. A current example of the consequences of the lack of identification is the almost complete lack of Indigenous disaggregation in the indicators for the Sustainable Development Goals [10,11].

Where Indigenous identification is in place in a country, estimates of the relative status of Indigenous people relative to non-Indigenous people are possible. It is important that identification of Indigenous people be determined using a common standard. In reporting rates, numerator and denominator should have common identification standards, consistently applied.

This is not often the case. New Zealand is the exception. In New Zealand there is a national health index which includes an Indigenous identifier. Death registrations are linked to the health identifier and Indigenous status from this record is used where not stated on the death registration [12].

In Australia, identification in the census drives the population estimates (denominator on mortality rates) while identification at death by family or funeral direc- tor drives the mortality estimates. Identification in both collections is incomplete, and varies over time, across geographical regions and across age and sex groups.

Canada does not have an identifier on death registrations and rely on linkage with other records to identify Indigenous deaths. Statistics Canada have linked the long form census to the Mortality Database to report on First Nations (status and non-status Indians), Métis and Inuit mortality [13]. In the US, race is recorded, but in order to resolve discrepancies on death certificates, there is a program of work currently under consideration by the National Center for Health Statistics. The project will use American Indian/Alaska Native census records linked to corresponding death certificates to correct racial errors and estimate American Indian/Alaska Native life expectancy [14].

\section{Good practice}

Views on good practice vary. Where there are entitlements associated with being accepted as Indigenous, the specific requirements for that entitlement will determine the method of identification. This concept is explored further in other papers in this special issue.

Identification practices should and do differ according the needs of the Indigenous peoples of each country. Through policies, legislation or self-identification, Indigenous identity should be more than just a 'check box' on a census form or blood quantum or genealog- 
ical proof of lineage, identity is personal, social, emotional, political, and financial (in some instances). Andersen and Smylie [15] argued that identification should include community identifying an Indigenous person as belonging to the group, but there have been a number of policies (residential or boarding schools, Sixties Scoop or Stolen Generations) that have led to Indigenous people being removed from their traditional territories and kinship ties that makes this difficult as well.

Not identifying at national level is not acceptable. Where countries have determined that there are risks associated with Indigenous identification for Indigenous peoples, systems need to be put in place to ensure that protections are included.

There is no gold standard for Indigenous identification. This does not mean that identification should not be included in national censuses and in birth and death registrations. Ideally it will also be included in administrative data collections, such as hospital records, child protection systems and the justice systems to enable monitoring of progress towards equity within coloniser countries for the Indigenous peoples of that country.

\section{Conclusion}

There is a clear and urgent need for national efforts to work with their Indigenous peoples to agree and implement a standard process for Indigenous identification.

One hundred and forty eight countries have signed the United Nations Declaration on the Rights of Indigenous Peoples. But the document is not legally binding and governments can determine when they will address the recommendations within the declaration. Identity is a key portion of the Declaration and it has been recommended at the United Nations that each country work with their Indigenous populations to implement the recommendations. This requires country governments to consult and collaborate with Indigenous groups around a wide variety of issues.

To assist with national efforts, and to share methods across countries, there should be international effort to identify good practice and to encourage identification. A session on the need for international effort was included in the 2018 International Association for Official Statistics (IAOS) conference, with a proposal for IAOS to form a working group of members and Indigenous representatives to scope and plan for such an effort.
All efforts need to be in conjunction with Indigenous peoples and in line with United Nations resolutions.

\section{References}

[1] Madden R, Jackson Pulver L. Aboriginal and Torres Strait Islander Population: More Than Reported Australian Actuarial Journal. 2009; 15(2): 27.

[2] The Constitution of the United States. Article 1, Section 2. Washington DC; 1789. Document No.: 2018-15679.

[3] United Nations. United Nations Permanent Forum on Indigenous Peoples, Factsheet. Who are indigenous peoples? 2007 [cited 201824 Aug]. Available from: http://www.un.org/esa/ socdev/unpfii/documents/5session_factsheet1.pdf.

[4] Office of Management and Budget. Revisions to the Standards for the Classification of Federal Data on Race and Ethnicity. Federal Register. 1997; 62(210): 9.

[5] Métis Nation. Who are the Métis? 2010 [cited 201824 Aug]. Available from: http://www.metisnation.ca/index.php/whoare-the-metis.

[6] Teillet J. The Boundaries of the Métis Nation 2011 [cited 2018 24 Aug]. Available from: http://www.metisportals.ca/cons/wp -content/uploads/2011/12/Boundaries-of-the-Metis-Nation2011.pdf.

[7] Anderson I, Robson B, Connolly M, Al-Yaman F, Bjertness E, King A, et al. Indigenous and tribal peoples' health (The Lancet-Lowitja Institute Global Collaboration): a population study. Lancet (London, England). 2016; 388(10040): 131-57.

[8] Jobe M. Native Americans and the US Census: A Brief Historical Survey University Libraries Faculty and Staff Contribution. 2004; 28.

[9] United States Census Bureau. Questions Planned for the 2020 Census and American Community Survey. 2018.

[10] Indigenous Peoples Major Group for Sustainable Development. Policy brief on Sustainable Development Goals and post-2015 development agenda: a working draft 2016 [cited 201827 Aug]. Available from: https://sustainabledevelopmen t.un.org/content/documents/6797IPMG\%20Policy\%20Brief \%20Working\%20Draft\%202015.pdf.

[11] Madden R, Coleman C. International Statistical Effort Needed to include Indigenous Peoples in SDGs and national statistics. 16th Conference of the International Association of Official Statisticians (IAOS); 19-21 September 2018; Paris 2018.

[12] Statistics New Zealand. New Zealand Period Life Tables: 2012-14 Wellington: Statistics New Zealand; 2015 [Available from: http://www.stats.govt.nz/browse_for_stats/health/life_ expectancy/NZLifeTables_HOTP12-14/Data\%20Quality. aspx].

[13] Statistics Canada. Mortality of Métis and Registered Indian adults in Canada: An 11-year follow-up study. Ottawa: Ministry of Industry 2009. Report No.: Ottawa: No. 82-003-XPE.

[14] Arias E. Towards the next generation of record linkage studies to advance data quality assessment of civil registrations in low and middle-income coutries. IUSSP-PAA-WBG Meeting on CRVS \& Record Linkage; 2016; Washington DC.

[15] Anderson MJ, Smylie JK. Health Systems Performance Measurement Systems in Canada: How Well do They Perform in First Nations, Inuit, and Métis Contexts? Pimatisiwin. 2009; 7(1): 99-115. 